\title{
Collaborative Learning and Innovative Assessment in Humanitarian Studies
}

\author{
Stephanie Burrell Storms \\ Fairfield University, sstorms@fairfield.edu
}

Melissa T. Labonte

Ana Marie N. Siscar

Susan F. Martin

Follow this and additional works at: https://digitalcommons.fairfield.edu/education-facultypubs Copyright 2014 Wiley Publishing for International Association The author's post-print has been archived here with permission from the copyright holder. The authors are grateful to the Teagle Foundation for its generous funding of this project and to our colleagues at Fairfield, Fordham, and Georgetown Universities for their ongoing support of and participation in this research.

\section{Repository Citation}

Burrell Storms, Stephanie; Labonte, Melissa T.; Siscar, Ana Marie N.; and Martin, Susan F., "Collaborative Learning and Innovative Assessment in Humanitarian Studies" (2014). GSEAP Faculty Publications. 116. https://digitalcommons.fairfield.edu/education-facultypubs/116

\section{Published Citation}

Burrell Storms, Stephanie L., Melissa T. Labonte, Ana Marie N. Siscar, and Susan F. Martin. "Collaborative Learning and Innovative Assessment in Humanitarian Studies." International Studies Perspectives (2014). DOI: 10.1111/ insp. 12081

This item has been accepted for inclusion in DigitalCommons@Fairfield by an authorized administrator of DigitalCommons@Fairfield. It is brought to you by DigitalCommons@Fairfield with permission from the rightsholder(s) and is protected by copyright and/or related rights. You are free to use this item in any way that is permitted by the copyright and related rights legislation that applies to your use. For other uses, you need to obtain permission from the rights-holder(s) directly, unless additional rights are indicated by a Creative Commons license in the record and/or on the work itself. For more information, please contact digitalcommons@fairfield.edu. 


\title{
Collaborative Learning and Innovative Assessment in Humanitarian Studies
}

\author{
Stephanie L. Burrell Storms \\ Fairfield University \\ Melissa T. Labonte (corresponding author) \\ Fordham University \\ Ana Marie N. Siscar \\ Fairfield University \\ Susan F. Martin \\ Georgetown University
}

\begin{abstract}
This article examines a multi-year project funded by the Teagle Foundation to assess student learning in humanitarian studies. It explores outcomes derived from developing a collaborative learning approach to humanitarian action that emphasizes both cross-campus and cross-institutional peer-to-peer learning and exchange. Faculty, staff, and students from Fairfield, Fordham, and Georgetown Universities worked together as members of the Jesuit Universities Humanitarian Action Network (JUHAN) to design an innovative and comprehensive assessment process for curricular programs in humanitarian studies, as well as courses with significant humanitarian content. In particular, we focus on the value of establishing cognitive and affective learning objectives; developing tools and methods to assess learning (e.g. rubrics and vignettes); demonstrating use of these tools through piloting and data analysis; and closing the assessment "loop." As the first of its kind assessment strategy for humanitarian studies at the undergraduate level, we argue that these efforts make important inroads in establishing a common baseline for measuring learning in the burgeoning field of humanitarian studies. They also contribute to preparing individuals for futures in the humanitarian profession and to becoming "men and women for and with others."
\end{abstract}

Stephanie L. Burrell Storms, Ed.D., is assistant professor of Multicultural Education in the Department of Educational Studies and Teacher Preparation at Fairfield University. Her research and teaching focus on educational outcomes of multicultural/social justice education, teacher action research, and program evaluation. Correspondence: Graduate School of Education \& Allied Professions, Canisius Hall, Room 220, Fairfield University, 1073 North Benson Drive, Fairfield, CT 06824; Tel: 203.254.3334; Email: sstorms@ fairfield.edu.

Melissa T. Labonte, Ph.D., is associate professor of political science at Fordham University. Her research and teaching focus on humanitarian politics, peacebuilding, multilateral peace operations, and human rights. Correspondence: Department of Political Science, Fordham University, Bronx, NY 10458; Tel: 401.339.3522; Email:

labonte@fordham.edu.

Ana Marie N. Siscar, Esq., is adjunct professor of international studies at Fairfield University and project director of the Jesuit Universities Humanitarian Action Network (JUHAN). Her research and teaching focus on international human rights and refugee law, global social justice, and immigration law. Correspondence: Center for Faith and Public Life, Fairfield University, 1073 North Benson Road, Fairfield, CT 06824; Tel: 203.254.2314; Email: asiscar@fairfield.edu.

Susan F. Martin, Ph.D., is Herzberg Professor of International Migration and director, Institute for the Study of International Migration at Georgetown University's Edmund A. Walsh School of Foreign Service. Her research and teaching focus on international migration, refugee policy, and humanitarianism. Correspondence: Edmund A. Walsh School of Foreign Service, Georgetown University, 3100 Harris Building, Washington, DC 20057; Tel: 202/687-2153; Email: martinsf@georgetown.edu. 


\section{Introduction}

Assessment can reveal a great deal about whether and how students connect and synthesize knowledge, as well as demonstrate effective communication, critical thinking, and experiential sense-making (Kille et al., 2008: 412). Thus, effective assessment enables educators and others to strengthen teaching and learning paradigms used in preparing students to examine complex issues such as the interdependence and tension among global actors, as well as the consequences of power imbalances, ingrained gender biases, and protracted crises. Indeed, developing innovative assessment reflects the realization that "[t]he world in which today's students will make choices and compose lives is one of disruption rather than certainty, and of interdependence rather than insularity" (AACU, 2011: 6). These considerations are especially relevant to fields of study such as international relations, globalization studies, and comparative politics.

Humanitarian studies and action represent an emerging sub-field where such approaches to learning and assessment can play an important role in ensuring students develop needed skills for careers in this area, and/or build humanitarian knowledge necessary to become global citizens more broadly. Heightened student awareness of and interest in this field of study have prompted some universities to examine pedagogical approaches and learning effectiveness. Obvious focal points are curricular offerings specifically centered on humanitarian issues (e.g. courses on international human rights and humanitarian law, humanitarian logistics, the causes of and effective responses to humanitarian emergencies) as well as those addressing closely related themes (e.g. the impact of humanitarian crises on global public health, economic development, and the environment). Such courses are often interdisciplinary and use a range of pedagogical 
techniques within the classroom, including lectures, classroom discussion and simulations, and role-playing exercises.

As students prepare for career paths in the field of humanitarianism and to become global citizens, it is vital to understand whether and how effectively institutions of higher learning, and the opportunities and programs they offer, are actually meeting objectives and goals. A critical element in determining the depth and breadth of learning in humanitarianism is assessment. Assessment comprises systematized processes maintained over time to gather, process, and analyze data to gauge student learning, and to use that knowledge to facilitate more effective decision-making about teaching and learning (Walvoord, 2010: 2), as well as curricular program design. It is also linked to skills development and essential learning outcomes that prepare students for careers, including international careers (Dolan, 2011: 437-8).

As members of the Jesuit Universities Humanitarian Action Network (JUHAN), Fairfield, Fordham, and Georgetown Universities are completing the final phase of a multi-year project funded by the Teagle Foundation to assess student learning in the context of humanitarian coursework and active learning through collaboration. Our article examines the processes involved in developing innovative assessment mechanisms for cross-campus and cross-course learning involving students, faculty, and institutions within the JUHAN network. In particular, we focus on the value of establishing cognitive and affective learning objectives, tools and methods to assess learning, (e.g. rubrics and vignettes), and closing the assessment "loop" meaning, using what we learned through conducting assessment to improve our program and teaching. We conclude by discussing how the lessons we draw from our research can be valuably extended into the study and use of assessment in other related sub-fields of international studies. 
First, however, we review briefly recent trends in the field of humanitarianism that have contributed to the growing need for rigorous humanitarian education at institutions of higher learning, and effective tools to measure learning that occurs within and across (and outside of) those institutions. We introduce JUHAN and its mission, which includes strengthening undergraduate curricula on humanitarian issues; providing service learning and other nonclassroom opportunities for students to engage in humanitarian action; fostering student leadership in developing effective means of aiding in humanitarian crises; and informing the ways in which Jesuit universities respond to humanitarian crises worldwide. We argue that these collaborations constitute important inroads in developing and institutionalizing the use of innovative assessment for curricular programs that focus on humanitarian studies and action. We then explore how collaboration by members of a dedicated assessment team led to the establishment of tailored cognitive and affective learning objectives. We then examine the processes through which these objectives were utilized to develop effective analytic rubrics to measure and gauge student learning, including formulating and implementing a pilot vignette as an effective, real-time affective learning assessment device and communications tool for use within the classroom. The results and data analysis of that piloting exercise are described. As the first of its kind assessment strategy for humanitarian studies, we conclude by elaborating on the implications of this project for learning and program development in the sub-field, its contribution to preparing individuals for futures in the humanitarian profession, and future planned collaborative research in this area.

\section{The growth of humanitarianism}

Contemporary trends in international relations signal the reality that many of our students are going to live out their lives as global citizens. For some, this means learning how best to 
integrate their idealism and knowledge to "make the world a better place." For others, it means integrating their idealism and knowledge into a professional career. Such careers are becoming increasingly appealing and tenable.

Characterized by an annual growth rate of $6 \%$, hundreds of thousands of staff and a global budget of U.S. \$6.6 billion, humanitarianism has become a full-fledged professional sector (Rainhorn et al., 2010: 6). The international nongovernmental organization (INGO) community alone comprises thousands of organizations, employs nearly half of all humanitarian aid staff, and expends U.S. $\$ 5.7$ billion annually. Six INGOs lead this part of the sector: Cooperative for Assistance and Relief Everywhere (CARE), Catholic Relief Services (CRS), Médecins Sans Frontières (MSF), Oxfam, Save the Children (SAVE), and World Vision International (Harvey et. al., 2010: 9-10; 17-20). Alongside the INGO portion of the humanitarian system, the UN and its specialized agencies, programmes, and funds, invest billions of dollars in funding for humanitarian efforts and employ hundreds of thousands of individuals who are, to use a Jesuit credo, "men and women for and with others." In 2012 alone, the United Nations Office for the Coordination of Humanitarian Affairs (OCHA 2013) managed consolidated appeals totaling U.S. $\$ 5.3$ billion for humanitarian responses in 21 countries affecting more than 50 million individuals. On average, these appeals have been increasing over time, with the most recent appeal (at the time of this writing) for the humanitarian crisis in Syria, U.S. $\$ 5$ billion, nearly matching the total for all funds managed throughout 2012 (BBC 2012).

Put plainly, the world is in greater need of what humanitarian aid workers do, which by extension means that the humanitarian system of the future will require higher levels of responsiveness; more innovation and future-oriented strategic thinking; and more well-qualified 
and educated humanitarian staff. ${ }^{1}$ Indeed, recent studies have shown that human resource competence is a critical component in explaining effectiveness outcomes in humanitarian action (People in Aid 2003; Webster and Walker, 2009). The most recent manifestation of this is the Joint Standards Initiative (JSI), which has developed a set of core professional and technical standards that have been widely adopted to ensure a competence baseline and are linked to effectiveness and accountability (Austin and O’Neil 2013)²

Traditionally, becoming a humanitarian aid professional required nothing short of baptism by fire. Aspiring aid workers plunged into the fray of the field, often working on shortterm contracts and moving from one insecure complex emergency environment to another. The focus was on "doing," whereas the knowledge and skills built through experience constituted the necessary training to propel individuals through successive assignments to higher roles and responsibilities within humanitarian agencies and organizations.

This method for achieving professionalization has not been without its drawbacks. First, it affects hiring and recruiting practices, which can be opaque, insular, exclusionary, and informal, based on who you know, rather than educational training or credentialing standards (People in Aid, 2003: 16; ELRHA, 2010: 9). Second, it has had an impact on aid effectiveness. The humanitarian system can claim many successes, but its track record is punctuated with colossal failures as well. Humanitarian response in the Darfur region of Sudan, Democratic Republic of Congo, and Rwanda, as well as the 2004 Tsunami and 2010 Haiti earthquake provided incontrovertible evidence of the importance of deploying competent and effective humanitarian aid professionals to the field.

\footnotetext{
${ }^{1}$ The authors are not making a normative judgment about the nature of this need. Rather, we recognize that humanitarian system's growth is attributable to many factors that can either enhance or impede effectiveness. ${ }^{2}$ Effectiveness is itself a contested concept - and the standards for measuring and assessing the practice of humanitarianism are the subject of an ongoing debate. For more, please see Barnett (2011); Barnett and Weiss (2008); Duffield (2001): and Weiss (2013).
} 
General perceptions of those working within the humanitarian system are that aid worker skills and professional profiles have either improved or stayed roughly the same compared with the past (Harvey et. al., 2010: 30, 36-37). Yet staff turnover remains high and recruiting and retaining highly skilled and qualified staff, particularly in volatile crisis environments, remains a significant challenge for most organizations.

\section{Linking humanitarian action back to and beyond the classroom}

As noted, becoming a humanitarian aid professional through experiential learning has remained largely the norm in the field, but this practice is coming under increased scrutiny. Many from inside and outside the sector are engaged in a robust debate regarding the potential that professionalization may hold for the field, including the relative wisdom of establishing certification standards, core competencies, accreditation structures, and professional associations for aid workers (Walker et. al., 2010; Walker and Russ, 2010). New thinking has emerged among scholars and practitioners regarding the desirability, practicality, and feasibility of establishing academic pathways to humanitarian sector careers. Such paths would focus on a combination of formal educational training to create core competencies and experiential learning.

Humanitarian professionals also need to have broad, interdisciplinary academic backgrounds that include exposure to fields such as anthropology and sociology; human rights; international law and organization; international politics; conflict resolution; social justice; peace studies; military studies; history; international political economy; communications and media studies; religion and theology; foreign languages; and organizational and supply chain management. As noted by the authors of one recent study (Rainhorn et. al., 2010: 9-10),

The humanitarian worker of today needs numerous skills. Being a doctor or an engineer is no longer sufficient preparation for a [crisis] response after an earthquake or dealing with the consequences of an armed conflict. As well as their basic technical training, humanitarian workers now need to have additional 
expertise in disciplines which are normally taught at university level. ... Despite the obvious good will of many who try, being a humanitarian is not a role that can be improvised. A humanitarian comes into being thanks to a number of very closely linked factors: experience, education, training and the century and a half old values of humanitarian action.

Currently the human resource needs of the humanitarian sector and the capacity of institutions capable of preparing individuals who would join this field—namely institutions of higher education - are not fully in sync. At the graduate and professional level, providers of humanitarian education, including universities, are in a catch-up phase. Nearly 80 graduate or professional-level humanitarian studies programs are currently offered globally across 50 universities. At the undergraduate level, where arguably the largest potential pool of future humanitarian aid workers begins their professionally-oriented education, there are fewer than five such programs offered globally (Rainhorn et. al., 2010: 11; 16). However, this number is increasing and there is a discernible, upward trend in the number of students expressing interest in pursuing formal programs of humanitarian studies.

It is important to note that formal education in and of itself may be necessary for the field's advancement, but will never be sufficient on its own to transform individuals into humanitarian aid workers. University training cannot teach students how to "behave in the field ... [and] one cannot ask academics and researchers to teach the basic skills of a job with which they have only a theoretical acquaintance" (Rainhorn et. al., 2010: 10). However, institutions of higher learning have the potential to strengthen professionalization in the humanitarian sector by leveraging the value of interdisciplinary knowledge-building, critical thinking, and analysis in order to better prepare students to confront the complexities that define this field of work, and to enter the profession having met assessable and measurable learning standards.

\section{The Jesuit Universities Humanitarian Action Network (JUHAN)}


Although by no means unique, Jesuit institutions of higher learning are ideally-suited to foster training in humanitarian studies and action, mainly because the vocation of humanitarianism and its constituent norms are highly congruent with the Jesuit mission and pedagogy. In particular, humanitarian norms align closely with the principle of "men and women for and with others," and the Jesuit educational principles of cura personalis and magis. Cura personalis derives from deep respect for the individual and his/her potential. Magis is reflected through striving to achieve personal excellence in the intellectual, emotional, moral, and physical aspects of life. Jesuit institutions also encourage students to embrace cosmopolitanism, to consider the world as the "home of the heart," and to think boldly, imagine creatively, love enthusiastically, labor tirelessly, and give generously.

Established in 2006, the Jesuit Universities Humanitarian Action Network (JUHAN) comprises 28 U.S.-based universities and colleges. ${ }^{3}$ It emerged as the result of a series of discussions between the Center for Faith and Public Life at Fairfield University, the Institute of International Humanitarian Affairs at Fordham University, and the Institute of the Study of International Migration at Georgetown University. Faculty within these institutions recognized the potential of university communities to mobilize and respond to humanitarian crises both locally and abroad and, importantly, reflected consensus concerning the need to improve student preparedness to enter the field of humanitarianism through enhanced pedagogy and assessment.

JUHAN has three principal goals: 1) to strengthen undergraduate curricula on humanitarian issues; 2) to provide service learning and other non-classroom opportunities for students to engage in humanitarian action; and 3) to inform the ways in which Jesuit universities respond to humanitarian crises worldwide. JUHAN actualizes these goals in programs and

\footnotetext{
${ }^{3}$ See http://www.juhanproject.org/. For a complete list of members, see http://www.fordham.edu/academics/programs_at_fordham_international_humani/undergraduate_educat/juhan/member _organizations_75769.asp.
} 
projects designed to stimulate critical interdisciplinary thinking among students about humanitarianism, including through active learning that emphasizes peer-to-peer exchange and inter-institutional collaboration. Through its programming, the network focuses on two types of students: those who intend to pursue careers in the humanitarian field; and those for whom the concept of global citizenship aligns with a desire to increase their knowledge of humanitarianism (Dolan, 2011).

A cornerstone of JUHAN activities is a biennial, network-wide undergraduate conference featuring an intensive, four-day immersion program that orients participants to all facets of humanitarianism and humanitarian action. Students and faculty engage closely with scholars, policymakers, and field-based practitioners with substantial experience in humanitarianism, and participate in focused learning that provides valuable insights and exposure to key sectors constituting humanitarian response (e.g. logistics, water, sanitation, and hygiene (WASH), food and nutrition, emergency shelter, health, coordination, human rights, civilian protection, security and early recovery). Other sessions focus on developing the leadership skills needed to organize effective, campus-based humanitarian responses to complex emergencies. Students share best practices in campus-organized humanitarian action and collaborate to develop and refine action plans for implementation when they return to their campuses.

Overall, JUHAN is a natural expression of the Jesuit pedagogical ideal of nurturing students to be "men and women for and with others." The network also promotes an educational paradigm that includes the interdependence and integration of academic learning, reflection, evaluation, and action. Through a combination of the pursuit of academic excellence and commitment to the education of the whole person, JUHAN seeks to develop in and across university communities a sound foundation for not only effective humanitarian action but also individual and institutional transformation. 
In 2008, Fairfield, Fordham and Georgetown Universities were awarded a multi-year grant from the Teagle Foundation to develop comprehensive learning assessment resources for humanitarian curricular programs and/or courses carrying significant content in issue areas closely related to humanitarianism. The resulting learning outcomes and assessment tools have significant potential to expand and deepen curricular programming and design, and communitybased learning opportunities that reflect the growing civic and academic responsibilities of higher education in response to domestic and international humanitarian crises in the $21^{\text {st }}$ century. The underlying paradigm for the project, while deeply rooted in a humanistic approach to learning, is aligned closely with broader goals associated with liberal arts education. These include empowering and preparing individuals to "deal with complexity, diversity, and change;" learning that reflects a "broad knowledge of the wider world as well as in-depth study in a specific area of interest;" developing a "sense of social responsibility as well as strong and transferrable intellectual and practical skills such as communication, analytical and problemsolving skills, and a demonstrated ability to apply knowledge and skills in real-world settings." Thus, its components are scalable to Jesuit and non-Jesuit colleges and universities globally.

\section{Assessment as a critical component of learning}

Assessment is a critical tool in accomplishing JUHAN's mission. In the context of education, it is defined as the "systematic collection of information about student learning using the time, knowledge, expertise, and resources available, in order to inform decisions that affect student learning" (Walvoord, 2010: 2). Two fundamental lines of assessment work have developed over the past 25 years — assessment for learning and assessment for accountability (Heiland and Rosenthal, 2011: 12). While accountability has become a guidepost for both the

\footnotetext{
${ }^{4}$ Liberal Education and America's Promise (LEAP): http://www.aacu.org/leap/.
} 
humanitarian system and systems of higher education more generally, the focus of JUHAN's assessment research and development aligns most closely with assessment for learning because our primary mission is to improve learning for those students who want to become global citizens and/or humanitarian professionals.

This process involved several initial steps. First, to assess curricular learning, the three partner universities devised common cognitive learning objectives and rubric traits for existing courses across a range of disciplines with significant humanitarian content. Second, and based on the realization that cognitive objectives can only mold students to the extent that attitudes and values drive them to act on their knowledge, the team developed a set of affective learning objectives. Together, the cognitive and affective learning objectives constitute a comprehensive set of learning outcomes. Third, the team devised and standardized a process to create vignettes as a formative and summative learning tool to measure cross-campus and cross-course learning. The assessment team's goal was to integrate these different aspects of assessment in ways that will shape the practices of educating students about humanitarian action, build their knowledge of the complexities and nuances that define humanitarianism, and facilitate the humanitarian imperative (e.g. caring and empathy) in identifying appropriate response actions.

Throughout the project, the team held the view that the value assessment brings to humanitarian education is both objective and attitudinal. As such, it consciously dealt with one of the classic faculty reservations about assessment: the ability of off-the shelf assessment instruments and forced-choice methods to fully reflect collegiate learning, and the tendency to "teach to the test" (Heiland and Rosenthal, 2011: 17). The team deliberated at length, for example, on the issue of whether and to what degree grading on the basis of rubrics, even if developed in close alignment with learning objectives, risked stripping student learning of its creativity. Further, the team was keen to avoid developing tools that would dumb down or dilute 
the goal of higher education to that which is measurable only in a narrow sense (Walvoord, 2010: 3). As a result of these considerations, the JUHAN team approached assessment as an initiative that should: 1) use learning outcomes to foster an active commitment to personal and social responsibility; 2) gauge and enhance a student's demonstrated ability to apply learning to complex problems and challenges; and 3) effectively prepare students for humanitarian action in the $21^{\text {st }}$ century (AACU, 2011: 9). ${ }^{5}$

We now examine in detail the four key dimensions of JUHAN assessment: establishing student learning outcomes, developing appropriate and effective tools to assess them, implementing those tools and analyzing initial pilot results; and closing the assessment loop.

\section{Student Learning Outcomes}

The first step in assessing academic program effectiveness is developing learning outcomes (Walvoord, 2011: 337). Learning outcomes generally describe three aspects of the learning and knowledge-building process: 1) knowledge; 2) values and attitudes; and 3) skills. Students should be able to demonstrate competence in each of these areas as a result of participating in a particular course or educational program (Allen, 2006: 35). These aspects of student learning reflect cognitive objectives, affective objectives, and behavioral objectives (Stassen et. al., 2004: 11). They can also be demonstrated in question form and should be designed holistically and tailored for specific courses. For example, what do faculty want students in a course to know?; to think or care about?; and to be able to do once they complete the program? We realize there are limits to our ability to address completely all three of these questions through assessment. To date our collaborative approach has dealt mainly with

\footnotetext{
${ }^{5}$ The team also integrated the goals of Liberal Education and America's Promise (LEAP) into its work. See http://www.aacu.org/leap/.
} 
assessment as it relates to the first two questions. Through experiential and active learning programs, however, there is potential to adapt assessment tools to address the third question.

An assessment team comprising faculty from Fairfield, Fordham, and Georgetown Universities developed 11 initial learning objectives for the program in fall 2007 (see Table 1). While not exhaustive, the team endeavored to capture as many dimensions of humanitarian action as possible through these objectives. Moreover, each objective was designed to prompt critical thinking and challenge conventional modes of inquiry regarding contemporary humanitarianism. Importantly, they were not formulated to reflect any single theoretical paradigm. Rather their construction was deeply informed by debate and dialogue regarding how different paradigms perceive and explain humanitarian action. And, the scope and range of identified learning objectives reflect the interdisciplinary nature of humanitarian action, permitting their use in courses drawn from disciplines such as history, sociology, anthropology, theology, philosophy, law, economics, international business, media and communication, literature, engineering, natural science, and political science. Team members also acknowledged the objectives would undoubtedly be tailored in their use by individual faculty members, and that this adaptability would be an important facet in both teaching and learning.

[Table 1 here]

The initial set of objectives was refined during the following year for piloting in a select range of existing courses containing significant humanitarian content. The objectives are also being utilized in courses that form part of Fordham University's Major and Minor in Humanitarian Studies, in JUHAN-designated courses and a planned Minor in Humanitarianism at Fairfield University, and the introductory course in the Certificate in Refugee and 
Humanitarian Emergencies at Georgetown University. ${ }^{6}$ Formalizing the integration of the learning objectives through new and existing programs which focus on humanitarian studies and action thus aids in ensuring that students receive exposure to the same set of learning objectives across a range courses. Traditional courses on humanitarianism (e.g., Humanitarian Action; Refugee Law; Conflict Resolution) address a majority of the cognitive objectives. At the same time and because of their interdisciplinary nature, these objectives could be suitably integrated in select components of courses featuring humanitarian content (e.g. English Literature; Art and Art History; Anthropology/Sociology; Economics; History; Philosophy).

Consequently, these types of courses have a broad reach among students as they are accessible to those who do not necessarily desire to become humanitarian aid workers but want to understand humanitarian issues as global citizens. And, another benefit of this approach to pedagogy and assessment has been that participating faculty are able to design relevant portions (or, in some cases, all) of their course instruction to complement the cognitive learning outcomes, thus lending coherence to overall course design (Stassen et. al., 2004: 6).

In addition to cognitive learning objectives, the assessment team also developed a series of affective learning objectives for course offerings with significant humanitarian content. Affective objectives are the stated attitudes, values, and dispositions faculty want students to be able to demonstrate through course learning and participation. Affective learning objectives are more difficult to measure than cognitive learning objectives and some argue that they are simply not "teachable" (Suskie, 2009).

Indeed, JUHAN faculty and staff evinced initial skepticism about being able to differentiate between affective objectives and cognitive objectives, and moreover, their

\footnotetext{
${ }^{6}$ See

http://www.fordham.edu/academics/programs_at_fordham_international_humani/undergraduate_educat/the_internatio nal_hu/index.asp, http://www.fairfield.edu/cfpl/cfpl_juhan_student.html, and http://isim.georgetown.edu/academics/refugees/.
} 
measurement. To overcome this, the team exercised great care in crafting the affective objectives, including identifying verbs that evoked attitudes, beliefs, and disposition rather than those that commanded cognition. For example, affective objective \#3 (see Table 2) requires students to articulate value for the role of mutually empowering action for all the participants. Compare this with the rubric for cognitive objective \#7 (see Table 1), which requires students to demonstrate understanding of the multiple beneficiaries of humanitarian action and identify particularly vulnerable groups. The former clearly requires students to convey normative knowledge while the latter requires demonstration of descriptive or explanatory knowledge.

Still, the distinction between the affective and cognitive objectives is not always readily apparent in the classroom context. Thus, one expression of support for the possibility of measuring affect in such settings involves students accessing the affect through knowledge. Interestingly, when the team considered measuring affective objectives in the context of active learning, they were quick to agree that it is important and feasible to measure affective objectives in this kind of learning environment. While accepting the challenges involved in measurement, the assessment team ultimately adopted the view that there are attitudes and dispositions vital for students to demonstrate in order to develop and nurture qualities associated with becoming men and women for and with others. These include actively committing to personal and social responsibility, participating meaningfully in humanitarian action, and expressing through their work the foundational principles and norms of humanitarian action: humanity, neutrality, solidarity, impartiality, transparency, and accountability. The team collaborated between fall 2010 and spring 2011 to finalize a group of 10 affective learning objectives (see Table 2).

[Table 2 here] 
Taken collectively, the cognitive and affective learning objectives provide the foundation for two of JUHAN's principle aims: strengthening the undergraduate curriculum on humanitarian issues; and informing the ways in which Jesuit universities respond to humanitarian crises worldwide.

\section{Tools to Assess Student Learning}

The next step in the assessment cycle involved selecting the measures to be used to determine whether students have met the stated learning outcomes (Walvoord, 2011: 342). Such measures can be direct or indirect. Direct measures require students to demonstrate their learning using a defined range of benchmarks, while indirect measures ask students to reflect on their learning (Allen, 2006). In consultation with assessment professionals at both Fairfield and Georgetown, two forms of direct measures were selected to assess student learning in JUHAN courses: rubrics and vignettes. We focus below on each of these measures.

Rubrics. Holistic and analytic rubrics are rating scales used to evaluate student performance on predetermined criteria such as learning objectives (Mertler, 2011). Holistic rubrics use a single scale to judge students' overall performance, whereas analytic rubrics are used to judge student performance on separate criteria and scales (Moskal, 2011). During fall 2007, the assessment team established a series of analytic rubrics to measure the cognitive learning objectives, as well as stimulate critical, interdisciplinary thinking among students. Each rubric has traits that define a specific objective and rate student response on a three-point nominal scale. ${ }^{7}$ The choice to use

\footnotetext{
${ }^{7}$ For example, cognitive learning objective \#1 focuses on key actors involved in humanitarian response. The objective was further disaggregated into three constitutive elements: identifying actors; analyzing actor interactions; and evaluating actor roles. Corresponding rubrics were then established to determine whether student knowledge exceeded, met, or was inadequate in relation to this objective. In the case of identifying actors, to exceed, students would need to identify all appropriate actors (e.g. local population, humanitarian agencies, political actors, civil authorities, mercenaries, military actors, churches and faith-based groups, media, commercial organizations, field researchers). To meet, students would need to identify most of the appropriate actors. Students who failed to identify most of the
} 
analytic rather than holistic rubrics aligned with the assessment team's desire to elicit focused responses from students for each criterion being measured.

However, some scholars argue that poorly designed rating scales can impact the ability to measure accurately deeper learning that may be difficult to define (Marcotte, 2006). To address this critique the initial rubric design underwent several rounds of revision following consultation with faculty, staff, and students from Fairfield, Fordham, and Georgetown Universities before being finalized and piloted in an international human rights course offered at Fairfield in fall 2010. ${ }^{8}$ Team members discussed individual rationales and expectations for rating, identified trends in student learning, and wrestled with how to score responses to some of the more relative or context-dependent learning objectives.

The assessment team has begun the process of refining the rubrics on the basis of the pilot. Suggested revisions include consolidating a number of individual rubrics into a single thematic rubric and modifying the nominal scale of measurement. The team also deliberated whether the rubrics could serve as a grading aid for course assignments, which could ensure consistency across traits being measured. This has the potential to facilitate collaboration and improve pedagogy and learning among faculty offering different courses at different institutions. The rubrics can thus serve as a common platform for incorporating humanitarian content into existing courses, streamlining assignments and grading, or in expanding curricular offerings.

appropriate actors were scored as having inadequate knowledge of this objective. A complete list of rubric traits is available upon request from the co-authors.

${ }^{8}$ Students were asked a series of questions designed to elicit demonstrated learning related to four of the cognitive learning objectives (\#s 1, 2, 7, and 10 - see Table 1 above) that had been predetermined by the instructor to be complementary to the overall learning goals for the course. 
Vignettes. In addition to utilizing analytic rubrics to measure student learning of cognitive learning objectives in JUHAN courses, the assessment team chose a secondary measure of learning through the use of vignettes. Vignettes are an example of authentic assessment and can prepare students for humanitarian action by providing them an opportunity to apply their own understanding and experience to a concrete situation that reflects a contemporary, real-world context. ${ }^{9}$ To complete a vignette exercise, students must use problem solving and critical thinking skills to identify the key dilemmas in the vignette, brainstorm possible action strategies, discuss why action should be taken, and determine which actions would be most effective and appropriate (Kunselman and Johnson, 2004).

Although this process serves as a proxy for humanitarian action, it may give us an idea about students' commitment to humanitarian action, their motivations for taking certain courses of action over others, and their preparation for future interventions. However, complex social issues may be difficult to capture accurately in a vignette, making it difficult to draw conclusions about students' actions in the future (Schoenberg and Ravdal, 2000). The goal of this assessment project, however, was not to predict whether students will intervene in humanitarian crises, but to assess their preparedness to engage in humanitarian action. Thus, the vignette developed for this project represents an accurate portrayal of real life events, which will improve the overall performance of the instrument (Schoenberg and Ravdal, 2000). To be clearp, vignettes are not the only tool that can be used to assess student learning, but they hold considerable promise as an innovative and authentic instrument in particular for affective learning alongsidecognitive learning.

The assessment team spent several months developing a vignette based on the issue of protection of civilians from sexual exploitation and abuse in humanitarian crises (see Table 3).

\footnotetext{
${ }^{9}$ For more on vignettes, see Barter \& Renold (2000). Authentic assessment is when the "assessment process is similar to or embedded in relevant real-world activities" (Allen, 2006: 227).
} 
This was a deliberate choice, informed mainly by shared content related to dilemmas of humanitarian action drawn from existing courses in which we intended to pilot the instrument. It also overlapped closely with a range of cognitive and affective learning objectives already established for these courses. Based closely on real events experienced by humanitarian aid workers and UN staff in West Africa during the early 2000s, the vignette details a situation to students and asks them to answer questions designed to gauge a range of select cognitive and affective learning objectives. ${ }^{10}$ The questions posed through the vignette were also designed so as to tap knowledge and affect concerning multiple learning objectives. This approach should help reduce mono-method bias and allow us to draw conclusions about the utility of this instrument as an assessment tool. ${ }^{11}$ For example, possible answers to vignette questions \#1 and \#3b could involve identifying key actors and appropriate beneficiaries (cognitive learning objectives \#2 and \#7). Possible answers to vignette questions \#2 and \#3 could involve identifying elements of effective humanitarian action (e.g. security, communication, coordination - cognitive learning objective \#10) and/or factors concerning the consequences of humanitarian crises (cognitive learning objective \#6 and affective learning objective \#2). The team also established a select bibliography related to the vignette, which faculty were encouraged to utilize to develop reading and discussion assignments in class sessions leading up to and following use of the vignette.

[Table 3 here]

\footnotetext{
${ }^{10}$ Cognitive learning objectives 2, 6, 7, 10, 11; and affective learning objectives 1, 2, 5, 6, 8, 10 (see Tables 1 and 2).

${ }^{11}$ Mono-method bias can occur when a single version of a measure is used in an instrument rather than structuring the instrument so that it measures the various parts of a broader concept or construct, and ensuring where possible that multiple measures of important or critical concepts are built into the instrument.
} 
The vignette was piloted in spring 2012 in a course at Fairfield University that explored the challenges of global politics and a course at Fordham University that examined issues of conflict analysis and resolution. The vignettes were administered to a total of 43 students at the beginning and end of both courses to measure both formative and summative learning. Students were given an allotted period of time in class to complete anonymously the vignette exercise. The learning objectives under focus were cognitive objectives \#2, 6, 7, and 10; and affective objectives \#2, 5, and 8 (see Tables 1 and 2).

Using the vignette toward the beginning of the course allowed the instructors to identify baseline levels of student knowledge and modify pedagogy or instructional focus so as to improve learning as the course proceeded. Administering the vignette at the end of the course allowed faculty to compare results with the initial application, thus helping to measure summative learning, as well as reducing mono-operation bias. ${ }^{12}$ In the interim period between the pre- and post-test administration of the vignette, the instructors utilized an identical set of select readings to engage students in extensive discussions focusing on gender, conflict, prevention of sexual abuse, civilian protection, and the implications of gender-based violence on communities transitioning away from conflict. Toward the end of the course, students were asked to respond again to the vignette, and were again given an allotted period of time in-class to complete anonymously the exercise.

During summer 2012, the pre- and post-tests were matched on the basis of identification numbers and, where necessary, demographic information such as gender/class year/major, resulting in an overall pool of 86 responses. A four-member assessment team including the two course instructors and two faculty members specializing in outcomes assessment finalized the

\footnotetext{
${ }^{12}$ Mono-operation bias, which can result when a single version of an instrument is implemented in a single place at a single time, affects construct validity (e.g. determining whether the constructs being measured are operationalized sufficiently through the instrument). Like mono-method bias (see footnote 9), mono-operation bias may also affect conclusion validity, which is correlated positively with standardizing the protocol for implementation and guidelines for coding.
} 
coding system in spring 2012. The team shared responsibility for coding the responses and entering the data into Mentor, a course management and assessment system. ${ }^{13}$

The initial results were discussed during a norming session in October 2012, during which time the team discovered that interrater reliability levels for select learning objectives were lower than expected. ${ }^{14}$ On this basis, the team developed a set of extensive coding guidelines for each of the learning objectives being measured. ${ }^{15}$ The guidelines clarified further a range of ideal-type content for each aspect of the coding scales. As a result of this process, one of the rubric traits reflected in cognitive learning objective \#10 (components of effective humanitarian action - "communication and coordination") was disaggregated into two separate traits, as was affective learning objective \#8 (“ambiguity/complexity”). These refinements enabled the coding team to seek out more discrete evidence in vignette responses for these factors and avoid conflating them in the assessment.

This methodical approach to formulating the assessment analysis guidelines also allowed for the unitization and distillation of data as well as identification of patterns in student responses. Student responses were measured against the cognitive learning objectives based on the established analytic rubrics, and assessment of affective objectives was recorded using content analysis. In particular, this latter method will allow assessors to identify the "what" and "why" behind students responses_-deepening our understanding of student learning (Patton, 2002). Having taken these steps to reduce, where possible, subjective differences in coding, the

\footnotetext{
${ }^{13}$ The course instructors coded the entire response pool, while two faculty with expertise in assessment each coded half of the response pool based on an odd/even system. Cognitive learning objectives were coded as follows: 1=inadequate; $2=$ meets expectations; $3=$ exceeds expectations. Affective learning objectives were coded as follows: $1=$ strongly disagree; $2=$ disagree; $3=$ agree; $4=$ strongly agree. The authors are grateful to Curt Naser at Fairfield University for this collaboration.

${ }^{14}$ Norming sessions are a key part of assessment, as they help ensure sufficient levels of "agreement between a particular set of judges on a particular instrument at a particular time" and establish trustworthiness of the data analysis. See Stemler (2004) on this point: http://PAREonline.net/getvn.asp?v=9\&n=4 (accessed 23 May 2011).

${ }^{15}$ Available upon request from the authors.
} 
pool was recoded and the data re-entered into Mentor. Interrater reliability improved considerably (see Table 4), thereby allowing the team to move forward with further analysis. ${ }^{16}$

\section{[Table 4 here]}

Cross-institutional comparisons of the vignette pilot data, carried out in spring 2013, yielded important insights for both cognitive and affective learning, and the utility of vignettes in service to this goal. Descriptive statistical analysis of the data included running means comparisons and correlational matrices. ${ }^{17}$ Overall, there was evidence of student learning across each of the cognitive and affective learning objectives and rubrics assessed, and the vignette exercise appears to be an ideal instrument allowing students to demonstrate both types of knowledge (see Table 5).

To confirm further the nature of the relationship between student responses to different learning objectives and their respective rubric measures, the team ran a correlation matrix using the pool of all responses (institutions combined) for the pre-test and the post-test implementation of the vignette. At the .05 and .01 levels, we found consistently strong correlations among key variables, suggesting that students were applying their knowledge across multiple concepts the learning objectives were designed to measure.

[Table 5 here]

\footnotetext{
${ }^{16}$ The only measure on which interrater reliability did not improve was "communication," which fell slightly from $64.4 \%$ to $63 \%$.

${ }^{17}$ The authors are grateful for the able assistance of Amy Boczer and Corey Wrinn in Fairfield University's Office of Institutional Research.
} 
In some cases, the results aligned with the assessment team's expectations. For example, cognitive learning objective \#2 (identifies key actors) was highly correlated with evaluating actors' roles, identifying appropriate beneficiaries, and analyzing interactions between actors. This finding makes sense given that knowledge concerning key actors is linked to knowledge concerning the roles these actors play and the interactions these actors have with one another. There was also evidence to suggest that knowledge between the pre- and post-test implementation of the vignette became more multidimensional and in-depth. For example, cognitive learning objective \#6 (consequences of humanitarian crises) was strongly correlated in the pre-test implementation of the vignette with only three other measures (analyzing interactions between actors; evaluating actors' roles, and identifying how beneficiaries are affected). However, in the post-test, this learning objective was strongly correlated with all other measures, suggesting that students were more aware of the deeper complexities associated with humanitarian crises and the interactive effect of the outcomes they spawn.

In other cases, however, the correlation matrix findings point to areas where further improvements can be made in order to explicate the connections between the concepts under focus. For example, the concept of legitimacy (a measure of cognitive learning objective \#10, effective humanitarian action) was correlated most strongly in pre-test implementation of the vignette to four other measures: identifying appropriate beneficiaries; identifying how beneficiaries are affected; communication; and coordination. Yet in the post-test, legitimacy was most strongly correlated to four completely different concepts: identifying key actors; mutual accountabilities; security; and consequences of humanitarian action. One way to interpret these results is to attribute them to the evolutionary nature of the learning process itself. In other words, these findings reflect just how dynamic the process of formative learning is. Students 
may well be grappling with the multifaceted dimensions associated with the concept of legitimacy, without necessarily settling in on some final understanding of what it comprises.

As concerns the affective learning objectives, strong correlations existed among all measures in the pre- and post-test implementation of the vignette. In particular, affective learning objective \#8 (ability to view a humanitarian crisis from multiple perspectives) was highly correlated to demonstrating commitment to the principle of do no harm/consequentialism; showing sensitivity to the gendered impact of humanitarian action; and demonstrating some level of comfort with complexity and ambiguity so often encountered in humanitarian crises.

The means comparison indicated significance among a number of the learning objective measures, including "identifies appropriate beneficiaries;" "security;" and "perspectives." 18 In terms of cognitive learning, pre-test measures indicated modest baseline knowledge among students concerning the overall consequences of humanitarian crises and, particularly, their effects on beneficiaries. Interestingly, student knowledge of these same factors experienced the most significant growth in the post-test measures. ${ }^{19}$ Lower levels of cognitive pre-test knowledge were evident across other measures, such as mutual accountabilities among actors on the ground; legitimacy and humanitarian action; and communication and coordination. In the post-test measures of these same factors, there were modest increases but overall the level of cognitive learning fell short of meeting expectations. In part, this may be due to the complex nature of these factors. For example, it is one thing to understand that humanitarian crises generate negative effects, but it is quite another thing to articulate specific causes and effects such as failure of accountability or actions that diminish the legitimacy of humanitarian action.

\footnotetext{
${ }^{18}$ At the .05 level. The affective learning objective "ambiguity" was also significant at the .1 level.

${ }^{19}$ Effects on beneficiaries experienced a .8 increase, and consequences of humanitarian crises experienced a .68 increase between the pre- and post-test implementation.
} 
Likewise, these findings may mean that greater emphasis on these factors is warranted in both classroom teaching and discussion, as well as the course readings.

In terms of magnitude of change in cognitive learning between the pre- and postimplementation of the vignette, the smallest increases in the mean rubric measures occurred in respondents' ability to identify a wide range of appropriate beneficiaries; evaluate actor roles in humanitarian crisis settings; demonstrate knowledge of how security needs must adapt and respond to changing situations; and articulate the necessity and challenges of effective communication and coordination. The most significant changes in the mean rubric measures occurred in respondents' articulation of the consequences of humanitarian action, effects on beneficiaries, mutual accountabilities, and identifying key actors overall.

An analysis of means comparisons of pre-test responses focusing on the affective learning objectives indicated that students exhibited low baseline values for all of the measures of concern (see Table 5). For example, initial levels of student sensitivity to the impact of humanitarian action on gender roles and relationships were not nearly as strong as the instructors expected. On the basis of the post-test means comparisons, however, students showed demonstrable increases across all measures for the affective learning objectives (moving from disagree or strongly disagree to agree in three of the four measures). In particular, respondents were able to articulate well their commitment to the principle of do no harm in examining the consequences of humanitarian actor responses to complex emergencies in the post-test.

Respondents also appeared to be relatively comfortable with the ambiguity and complexity inherent in the vignette scenario, and their ability to communicate multiple perspectives in interpreting the implications of the humanitarian crisis improved. While female respondents demonstrated slightly higher mean levels of knowledge across nearly all learning objectives, there were no discernible gender gaps in overall learning between the pre- and post-test. Perhaps 
most notably, however, student sensitivity to the impact of humanitarian action on gender roles and relationships experienced the greatest increase of all the objectives measured (cognitive and affective), from an initial mean score of 1.74 in the pre-test to 2.79 in the post-test. ${ }^{20}$

The assessment team recognizes that while the vignette appears to hold promise as a tool for assessing affective and cognitive learning, there are limits to our ability to generalize from it. Two issues linked to construct validity warrant some concern, but do not detract from our findings overall. First, it is possible that some students may engage in hypothesis guessing while completing the vignette. This could have the effect of conditioning student responses so they align with what students presume their instructors are trying to measure through the vignette instrument, and then adjust their responses accordingly. Second, it is possible that some students may experience evaluation anxiety or apprehension in completing the vignette, which would result in responses that are either too basic or too overthought. Both of these challenges can be managed but not eliminated, and wider implementation of the vignette across different courses should aid in minimizing their effects.

Closing the loop. After concluding this cycle of assessment development, piloting, review, and revision, the final phase has been focused on closing the assessment loop by engaging the evidence from the implementation of the assessment tools to improve student learning and curricular programming. The end of assessment is action (Walvoord, 2010: 3), which for JUHAN's purposes involves strengthening and leveraging the network of Jesuit universities to deepen student learning of humanitarian action. The assessment instruments developed by Fairfield, Fordham, and Georgetown will be used again in courses during the 2013-2014 academic year, and are currently being used for Fairfield University's JUHAN curricular

\footnotetext{
${ }^{20}$ See footnote 11.
} 
programming, and Fordham University's course assessment of its M.A. Program in Humanitarian Action (MIHA) and in its Humanitarian Studies Major and Minor. The authors have also presented segments of this research at five professional conferences, including the 2011 World Conference on Humanitarian Studies; the 2011 International Association for the Study of Forced Migration conference in Kampala, Uganda; the 2012 Middle States Commission on Higher Education conference; the 2013 Commitment to Justice in Jesuit Higher Education conference; and the 2013 International Studies Association-Northeast Conference.

Select information from the project has also been integrated into a toolkit that was disseminated to more than 100 individuals and institutions worldwide in 2012 (JUHAN, 2012). ${ }^{21}$ We anticipate that these findings and information-sharing efforts will be useful not only to institutions that constitute JUHAN, but also to others interested in developing curricular programming and assessment that focuses on humanitarian issues as well as other fields. One venue for sharing these findings and a revised, updated version of the toolkit will be at the next biennial JUHAN Conference in 2015 where Jesuit and non-Jesuit institutions involved in humanitarian and social justice education will participate. This venue will also serve as a forum at which faculty who have utilized the toolkit can provide feedback on its use across a range of disciplines and courses, and to offer suggestions for further improvements. Additionally, the team is in the initial stages of developing new vignettes that reflect other learning objectives and key issues at the center of humanitarian studies. To reiterate, the assessment team's broader goal is to shape the program and practices of educating students about humanitarian action, build their knowledge of the complexities and nuances that define humanitarianism, and facilitate the humanitarian imperative (e.g. caring and empathy) in identifying appropriate response actions.

\footnotetext{
${ }^{21}$ The toolkit features the cognitive and affective learning objectives, the learning rubrics, copies of course syllabi incorporating the objectives, the case study vignette, other assessment instruments, and select reference material for instructors and students. Copies are available from the co-authors upon request.
} 


\section{Conclusion}

As noted at the outset, many students want to build lifelong knowledge of humanitarian issues and contribute in some fashion as global citizens. It is also the case that students are less likely than in past to perceive humanitarian work as a deviation on their path to other occupations or vocations. They increasingly view this field as holding distinct promise, both over the long term and in its own right. The drive for professionalization in the humanitarian system is expected to continue well into the future (Austin and O'Neil 2013) and will depend more and more on well-educated and well-trained junior staff to fill its ranks.

JUHAN has attempted to enhance the learning that both types of students experience by developing innovative assessment tools. And, as its assessment tools and toolkit are refined and used more widely, the long-term measurement and analysis of student learning in this collaborative environment should become a key element in shaping and developing humanitarian studies in ways that reflect the realities of the humanitarian profession, but also provide broader experiences linked to international studies for students and faculty as well.

Cross-institutional assessment, we argue, is a key step in ensuring that the common platform of learning objectives is delivering on its goal of strengthening undergraduate curricula on humanitarian issues, as well as simultaneously facilitating a tailored approach to learning at specific JUHAN and non-JUHAN institutions. In the case of the humanitarian curricular development that has taken place at Fairfield, Fordham, and Georgetown Universities, developing innovative assessment strategies to gauge student learning has become both more appropriate and necessary. 
It has also provided a forum through which to engage in cross-institutional collaboration on course content and design, and information sharing on pedagogy - all of which should enhance student learning. JUHAN partners plan to continue to work closely in fine-tuning and expanding assessment tools and techniques, including analytic rubrics and vignettes, with which to gauge both cognitive and affective student learning. In this way, we may be making important inroads into not only how assessment can be innovated to meet individual institutional needs, but also to generate evidence-based analysis from which to develop future approaches to measuring learning and knowledge in the field of humanitarian studies.

In looking to the future, this partnership to develop value-added learning and innovative assessment tools and resources for humanitarian studies could be expanded to a range of curricular and community-based activities in other related issue areas such as international law, gender and women's studies, peace studies, environmental and development studies, and social justice. For example, courses in international law can utilize JUHAN cognitive learning objectives that focus on questions of the laws of war, which include discussions about humanitarian intervention and use of force in response to humanitarian crises. Courses on gender studies can incorporate JUHAN affective learning objectives linked to the gendered nature of humanitarian crises as well as the power asymmetries they produce. Relatedly, faculty and staff at institutions of higher learning find themselves being asked to adopt more rigorous methods of assessment and accreditation bodies are requiring evidence of demonstrated learning among our students.

The tools created by the JUHAN assessment team can augment much of the assessment that we know already occurs in higher education because they reflect best practices. At the same time, they represent the cross-cutting nature of learning because humanitarian studies is, by definition, interdisciplinary. These efforts may well contribute to the growing trend toward 
preparing global citizens, and ultimately may help the humanitarians do what they do in the field and at headquarters more effectively — to be learned men and women for and with others. 


\section{References}

Allen, MARY J. (2006) Assessing general education programs. Bolton, MA: Anker Publishing Company.

ASSOCIATION OF AMERICAN COLLEGES AND UNIVERSITIES (2011) The LEAP Vision for Learning: Outcomes, Practices, Impact and Employers' Views. Washington, DC: Association of American Colleges and Universities.

Austin, LoIS And Glenn O’NeIL. (2013) The Joint Standards Initiative: Global Stakeholder Consultation Report. Available at http://pool.fruitycms.com/humanitarianstandards/News/FINAL-JSI-StakeholderConsultation-Report.pdf (accessed 3 June 2013).

BARNETT, MichaEL. (2011) Empire of Humanity: A History of Humanitarianism. Ithaca, NY: Cornell University Press.

Barnett, Michael AND Thomas G. Weiss, eds. 2008. Humanitarianism in Question. Ithaca, NY: Cornell University Press.

BARr, RoBert B. AND John TAgG. (1995) From Teaching to Learning: A New Paradigm for Undergraduate Education. Change 27: 13-25.

BARTER, CHRISTINE AND EMMA RENOLD. (2000) I wanna' tell you a story: Exploring the application of vignettes in qualitative research with children and young people. International Journal of Social Research Methodology 3 (4): 307-323.

BBC. (2013) Syria crisis: UN launches largest ever aid appeal, 7 June 2013, available at: http://www.bbc.co.uk/news/world-middle-east-22813207 (accessed 8 June 2013).

Dolan, CHRIS. (2011) From Scratch: Designing and Implementing a New International Studies Program at a Small College. International Studies Perspectives 12 (4): 428-446.

DUFFIELD, MARK. 2001. Governing the Borderlands: Decoding the Power of Aid. Disasters 25 (4): 308-320.

ENHANCING LEARNING AND RESEARCH FOR HUMANITARIAN ASSISTANCE (ELRHA). (2010) International Working Forum on Professionalising the Humanitarian Sector. Cardiff, U.K.: Enhancing Learning and Research for Humanitarian Assistance (ELRHA) and Save the Children.

Harvey, Paul, Abby Stoddard, Adele Harmer, And Glyn Taylor. (2010) The State of the Humanitarian System: Assessing Performance and Progress A Pilot Study. London: Active Learning Network for Accountability and Performance in Humanitarian Action (ALNAP)/Overseas Development Institute.

HeIland, Donna. \& Rosenthal, Laura J., eds. (2011) Literary Study, Measurement and the Sublime: Disciplinary Assessment. New York: The Teagle Foundation.

JESUIT UNIVERSITIES HUMANITARIAN ACTION NETWORK (JUHAN) (2012) JUHAN Assessment Toolkit for Universities' Humanitarian Engagements. Fairfield, CT: Fairfield University.

KiLle, Kent J., MAtTHEW Krain, AND JefFrey S. LANTIS. (2008) Active Learning across Borders: Lessons from an Interactive Workshop in Brazil. International Studies Perspectives 9 (4): 411-429.

Kunselman, JuliE C. AND KATHERINE A. JOHNSON. (2004) Using the case method to facilitate learning. College Teaching 52 (3): 87-92.

Marcotte, Madeline. (2006) Designing Building a Better Mousetrap: The Rubric Debate, Viewpoints 7 (2). Available at: http://faculty.ccp.edu/dept/viewpoints/w06v7n2/rubrics1.htm. (Accessed 21 May 2012).

Mertler, CrAig A. (2001) Designing scoring rubrics for your classroom. Practical Assessment, Research \& Evaluation 7 (25). Available at: http://PAREonline.net/getvn.asp?v=7\&n=25. (Accessed on 22 April 2011). 
Moskal, BArbara M. (2000) Scoring rubrics: what, when and how?. Practical Assessment, Research \& Evaluation 7 (3). Available at: http://PAREonline.net/getvn.asp?v=7\&n=3. (Accessed 22 April 2011).

OFFICE FOR THE COORDINATION OF HUMANITARIAN AFFAIRs (OCHA). (2013) Overview of the 2012 Consolidated Appeals and Comparable Humanitarian Action Plans (New York: United Nations-OCHA).

PATTON, MiCHAEL QUINN. (2002) Qualitative research and evaluation methods. 3rd ed. Thousand Oaks, CA: Sage.

PEOPLE IN AID. (2003) Code of good practice in the management and support of aid staff. London: People in Aid.

RAinhorn, JeAn-DANiEl, Amna Smailbegovic, AND SABIne JiEKAK. (2010) Humanitarian Studies 2010: University Training and Education in Humanitarian Action. Geneva: University of Geneva Graduate Institute).

Schoenberg, NANCY A. AND Hege Ravdal. (2000) Using Vignettes in Awareness and Attitudinal Research. International Journal of Social Research Methodology 3 (1): 63-74.

Stassen, Martha L. A., Kathryn Doherty, and Mya Poe. (2004) Program-Based Review and Assessment: Tools and Techniques for Program Improvement. Amherst, MA: University of Massachusetts, Amherst. Available at http://www.umass.edu/oapa/oapa/publications/online_handbooks/program_based.pdf. (Accessed 22 April 2011).

Stemler, SteVen E. (2004) A Comparison of Consensus, Consistency, and Measurement Approaches to Estimating Interrater Reliability. Available at http://PAREonline.net/getvn.asp?v=9\&n=4. (Accessed 23 May 2011).

SuskiE, LINDA. (2009) Assessing student learning: A common sense guide. $2^{\text {nd }}$ ed. San Francisco: Jossey-Bass.

Walker, Peter And CATHERIne Russ. (2010) Professionalising the Humanitarian Sector: A Scoping Study. Cardiff, U.K.: Enhancing Learning and Research for Humanitarian Assistance (ELRHA) and Save the Children.

Walker, Peter, Karen Hein, Catherine Russ, Greg BertlefF, and Dan Caspersz. (2010) A Blueprint for Professionalizing Humanitarian Assistance. Health Affairs 29 (12): 2223-2230.

WALVOORD, BARBARA E. (2011) How to construct a simple, sensible, useful departmental assessment process, pp. 335-352 in Heiland, Donna and Laura J. Rosenthal, eds., Literary Study, Measurement, and the Sublime: Disciplinary Assessment. New York: The Teagle Foundation. . (2010) Assessment Clear and Simple: A Practical Guide for Institutions, Departments, and General Education, 2nd ed. San Francisco: Wiley.

Webster, MACKINNON AND PETER WALKER. (2009) One for All and All for One: Intraorganisational Dynamics in Humanitarian Action. Medford, MA: Feinstein International Center, Tufts University.

Weiss, Thomas G. 2013. Humanitarian Business. Cambridge, U.K.: Polity Press. 
1. articulate a common understanding of the concept of humanitarian crises

2. identify and understand the roles and interactions among key actors in humanitarian response

3. demonstrate understanding of factors the key actors take into account in determining whether to intervene during humanitarian crises

4. demonstrate an understanding of the causes of humanitarian crises

5. recognize and understand the phases of humanitarian crises

6. demonstrate an understanding of the consequences of humanitarian crises

7. understand the multiple beneficiaries of humanitarian action, identify particularly vulnerable groups and articulate ways in which beneficiaries interact with other humanitarian actors

8. demonstrate an awareness about how gender expectations make some members of communities vulnerable/potentially exploitable in humanitarian crises

9. differentiate between the consequences of military intervention for humanitarian reasons and humanitarian action by civil interests and describe the ways in which these two modes of humanitarianism interact

10. describe the utilization of appropriate components of humanitarian action

11. demonstrate ability and willingness to continually question the effectiveness of humanitarian responses and adapt accordingly 
1. adhere to the core principles of humanitarian action that all possible steps should be taken to prevent or alleviate human suffering

2. demonstrate a commitment to the principle of do no harm in examining the consequences of their actions on humanitarian crises

3. show value for the role of mutually empowering action for all the participants

4. show value for democratic principles of participation

5. show sensitivity to the impact of humanitarian action on gender roles and relationships

6. communicate a sense of fulfillment when they take humanitarian action

7. demonstrate a belief that their individual intervention in a global social problem is both possible and consequential

8. be able to view a humanitarian crisis from multiple perspectives, and they are more comfortable with complexity and ambiguity

9. be more respectful of, and open to learning about others' beliefs and cultures

10. demonstrate a commitment to address humanitarian crises regardless of where they occur 
Table 3. JUHAN vignette

You are a member of an NGO team visiting three conflict-affected nations in West Africa. Your team is conducting a research study on the vulnerabilities of refugee children that will be shared with UN agencies and other humanitarian NGOs. You and members of your team meet with groups that include refugees, returnees, local populations, internally displaced persons and humanitarian aid workers. In the course of your research, you and your team unexpectedly hear numerous allegations of abuse by humanitarian workers. Young girls report exchanging sex for urgently needed humanitarian assistance, including soap, medicines, food, and in some cases, money. In other testimony, women who do not receive adequate food rations in the camps are forced into prostitution to feed their families. One woman reports to your team: "I leave my child with my little sister, who is ten years old, and I dress good and I go where the NGO workers drink or live and one of them will ask me for sex, sometimes they give me things like food, oil, soap and I will sell them and get money." Similar claims are made in focus groups and interviews in all three countries, across dozens of internally displaced person (IDP) and refugee camps that are hundreds of miles apart. When tallied, your team finds allegations concerning more than 50 perpetrators, 40 aid agencies, 40 child victims, and 80 separate sources.

1. What is your assessment of the situation?

2. List the conditions or factors that may have contributed to the situation.

3. What actions, if any, would you take to address this situation?

(a) Why have you chosen these actions?

(b) Will they be effective? For whom? Why or why not?

(c) Are there potential negative effects to taking action? If so, what are they? 
Table 4. Interrater Reliability

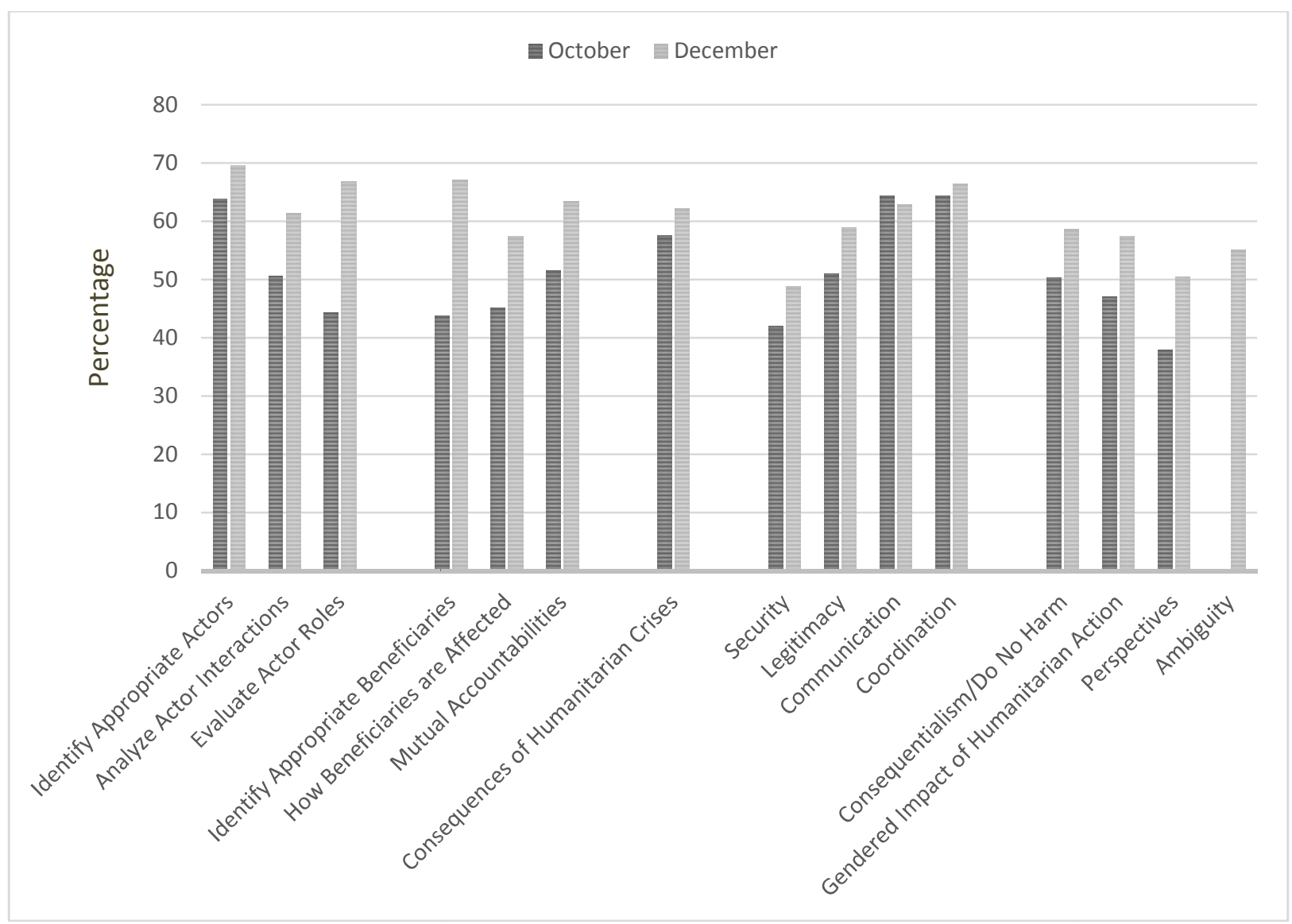


Table 5. Means Comparison (institutions combined)

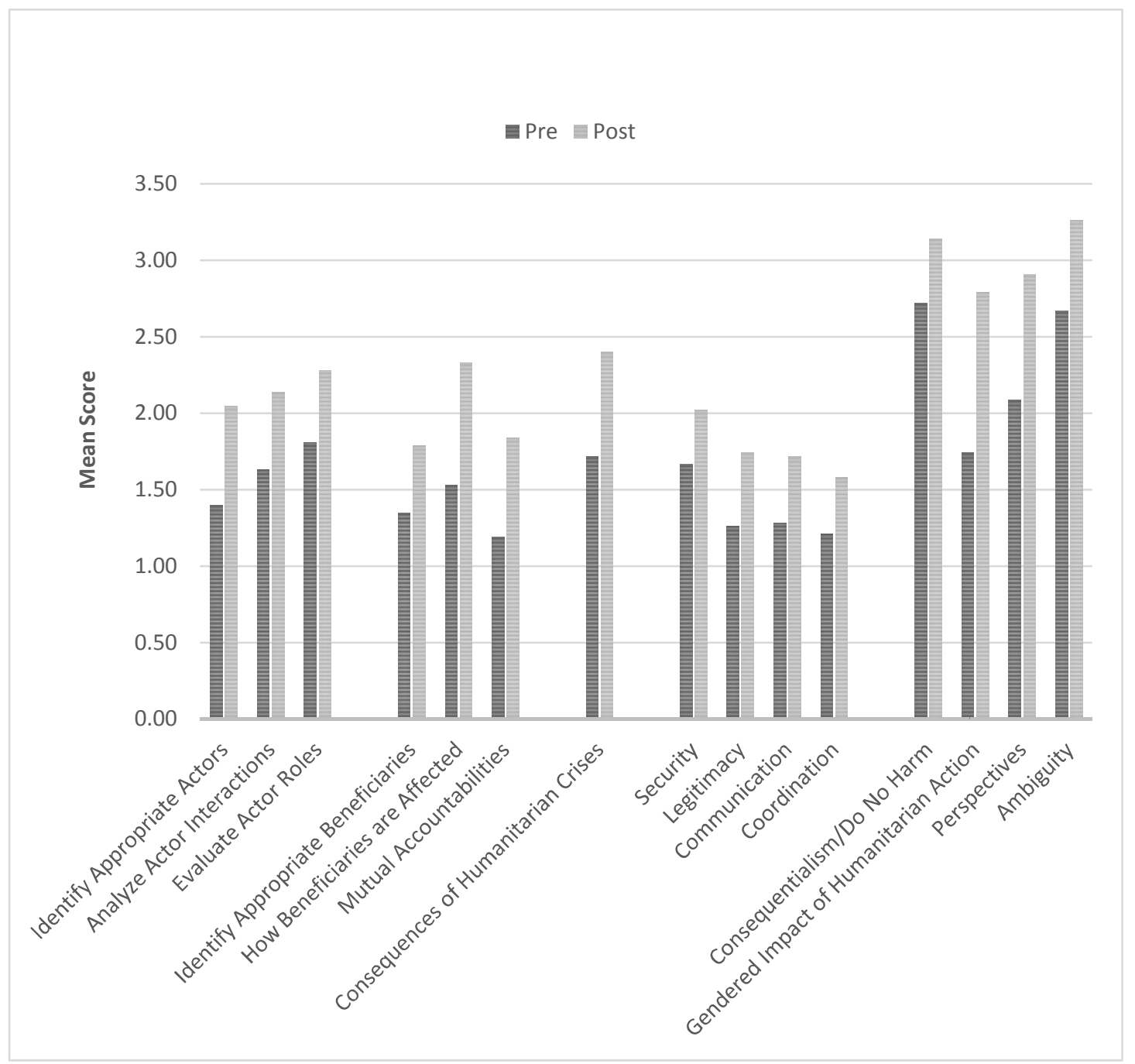

